Article

\title{
Studies on Energy Dissipation Mechanism of an Innovative Viscous Damper Filled with Oil and Silt
}

\author{
Zheng $\mathrm{Lu}^{1,2}\left(\mathbb{D}\right.$, Junzuo $\mathrm{Li}^{1}$ and Chuanguo Jia ${ }^{3,4, *}$ \\ 1 Research Institute of Structural Engineering and Disaster Reduction, Tongji University, \\ Shanghai 200092, China; luzheng111@tongji.edu.cn (Z.L.); 1732580@tongji.edu.cn (J.L.) \\ 2 State Key Laboratory of Disaster Reduction in Civil Engineering, Tongji University, Shanghai 200092, China \\ 3 Key Laboratory of New Technology for Construction of Cities in Mountain Area, Chongqing University, \\ Ministry of Education, Chongqing 400045, China \\ 4 School of Civil Engineering, Chongqing University, Chongqing 400045, China \\ * Correspondence: jiachuanguo@cqu.edu.cn; Tel.: +86-21-6598-2668; Fax: +86-21-6598-2224
}

Received: 20 March 2018; Accepted: 22 May 2018; Published: 29 May 2018

check for updates

\begin{abstract}
To improve seismic performance of a traditional viscous damper, an innovative viscous damper is proposed, in which the conventional damping medium is replaced by a mixture of oil and silt. This new medium is expected to increase damping force and solve the problem that arises out of the fact that the energy dissipation capacity of a conventional fluid viscous damper is low for small displacements. Firstly, the design concept and device configurations are introduced, then a cyclic loading test is applied to investigate the damper's energy dissipation mechanism in different conditions. Experimental results show that the damper exhibits displacement-dependent characteristics for small displacements, indicating that the silt has changed its damping mechanism. Furthermore, the effect of multiple test parameters on the damping force is analyzed, showcasing that an increase in silt content can visibly increase the damping force. According to experimental data, fitting models of the damping force are obtained and verified, thus promoting further engineering applications.
\end{abstract}

Keywords: viscous damper; hybrid damper; seismic performance; cyclic loading test; silt

\section{Introduction}

The use of passive, semi-active, and active dampers to dissipate seismic energy is an effective approach in the creation of earthquake-resilient structures [1-4]. Such energy dissipation devices reduce structural seismic response and protect the structure from severe damage. As a type of passive damper, viscous dampers were firstly used as shock absorbers in mechanical engineering [5]. Makris and his group then began studying viscous dampers in civil engineering applications [6]. A fractional derivative Maxwell model was proposed for viscous dampers, which were used for vibration control and seismic isolation of buildings [6]. Fluid viscous dampers fabricated by Taylor Devices have been applied to hundreds of bridges and buildings, displaying satisfactory performance [7]. To further improve performance, semi-active viscous dampers, such as variable orifice dampers and magnetorheological (MR) dampers, were investigated [8,9]. These semi-active dampers can adjust damping forces through variable ways, such as changing the area of the orifice or changing the state of the damping medium to satisfy different excitations. Taylor and his group applied fluid viscous dampers in a high-rise structure in order to suppress anticipated wind-induced accelerations [10]. Viscous dampers have been proven to be useful to reduce structural vibration under both wind and earthquake excitations $[10,11]$. In addition, other scholars have also investigated performance tests, analytical models, design methods, and other aspects of viscous dampers [12-15]. Constantinou 
and Symans proved that viscous dampers could reduce both inter-story drifts and shear forces of a structure [12]. A research by Taylor and Constantinou presented the test methodology, procedure and results of full-scale viscous dampers with high-output forces, which was useful for further research [14]. Furthermore, many scholars have focused on the optimum design of viscous dampers for high-rise buildings [15]. The advantages of viscous dampers include their ability to not contribute to additional stiffness of a structure and great energy dissipation capacity. However, shortcomings do exist.

Viscous dampers are velocity-dependent. Compared to velocity-independent dampers such as friction dampers [16,17], viscous dampers have much lower energy dissipation capacity for small displacements [18]. In engineering applications, the performance of the damper is limited when structural displacements are not large enough to activate them [19]. Hence, some displacement amplification methods were studied. Berton and Bolander designed an amplification device based on a gear-type mechanism and verified the device's function through laboratory tests [20]. In addition, Ribakov et al. suggested magnification of the effect of viscous dampers by lever arms [21]. However, these methods make a structure more complicated and increase manufacturing costs, proving unfavorable to a wide range of engineering applications.

A multiple damping mechanism is an effective way to reduce the primary structure's response [22,23]. Tsai et al. combined velocity-dependent and velocity-independent devices in one frame, minimizing the shortcomings of individual dampers and effectively reducing structural response [24]. Marko et al. studied the seismic response of a structure equipped with multiple types of dampers [25]. Furthermore, some dampers with hybrid energy consumption mechanisms were designed to enhance damping performance [26-30]. Lee and his group developed a new hybrid energy dissipation device, combining a steel slit damper and rotational friction dampers [27]. Lu studied the performance of particle dampers that had several energy dissipation mechanisms [29]. Inspired by these experiences, a new type of viscous damper with a mixed damping medium consisting of silt and silicone oil is proposed in this paper.

As a very common engineering material, the dynamic properties of soil have been studied by scholars, who found that the deformation process of soil also dissipates energy [31-33]. The elastic-plastic model, which is displacement-dependent, is usually applied as the constitutive model of the silt. This research attempts to enrich the damping mechanism of the viscous damper by adding silt into the conventional damping medium. The high pressure in the cylinder of the damper can force the saturated silt to deform and dissipate energy. In addition, the connection between particles of saturated silt is weak, while its fluidity and viscosity is strong $[34,35]$. Therefore, the mixed medium has enough fluidity, and viscosity is increased to enhance the damping force.

This paper investigated this new type of viscous damper. A corresponding performance test was carried out to study its energy dissipation mechanism and a simplified damping force model was proposed (based on experimental results) to facilitate further engineering applications.

\section{Conceptual Design of Innovative Viscous Damper}

\subsection{Viscous Fluid Design}

Methyl silicone oil is a commonly used energy dissipation medium for viscous dampers. Table 1 lists its physical properties. It has excellent electrical insulation tolerance, temperature tolerance, and high compression modulus. It is hydrophobic and chemically inert, with small surface tension and viscosity-temperature coefficient. 
Table 1. Physical properties of methyl silicone oil.

\begin{tabular}{cc}
\hline Density $/ \mathrm{kg} / \mathrm{m}^{3}$ & 970 \\
Kinematic viscosity $/ \mathrm{cst}\left(25^{\circ} \mathrm{C}\right)$ & $1000 \pm 50$ \\
Dynamic viscosity $/ \mathrm{kg} /(\mathrm{m} \cdot \mathrm{s})\left(25^{\circ} \mathrm{C}\right)$ & 0.97 \\
Flash point $/{ }^{\circ} \mathrm{C}$ & 300 \\
Freezing point $/{ }^{\circ} \mathrm{C}$ & -50 \\
\hline
\end{tabular}

The silt applied in the test is shown in Figure 1a. Through moisture content test and sieve test, the specimen can be classified as low-plasticity silt, which is homogeneous with very little impurities. The particles are very small, like powder. Furthermore, the moisture content is $0.906 \%$, which is extremely low. The plasticity index $I_{p}=9.6$. On mixing the silt with methyl silicone oil, it was found that the mixed medium was fluidic after stirring and had great viscosity.

Firstly, the silt increases the viscosity of the damping medium and the maximum damping force. Furthermore, special dynamic characteristics change the original energy dissipation property of the viscous damper by bringing in a multiple energy dissipation mechanism. Seismic energy is not only dissipated by viscous damping, but also by the deformation of the silt particles and the friction between the particles and the cylinder. The reciprocating motion of the piston forms a relative movement between the silt and the silicone oil. At the same time, the silt is in a suspended state, where contact between the particles is rare. Hence, the fluidity of the mixture is enhanced. In addition, the excess pore pressure reduces the effective shear stress between the silt particles, which increases fluidity as well.

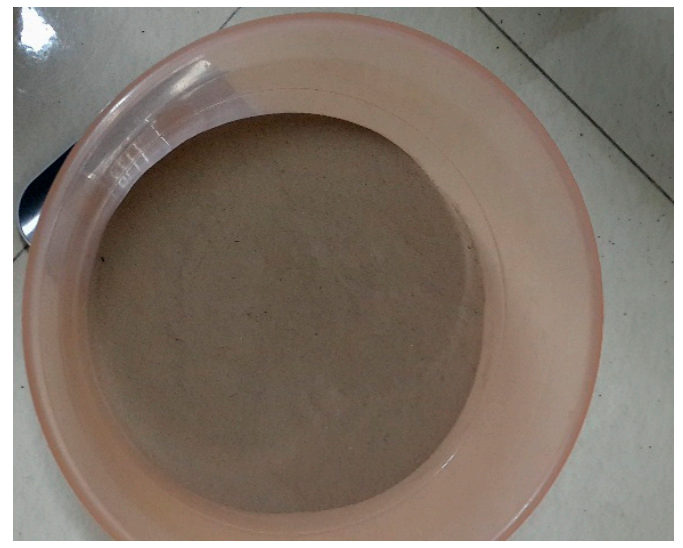

(a)

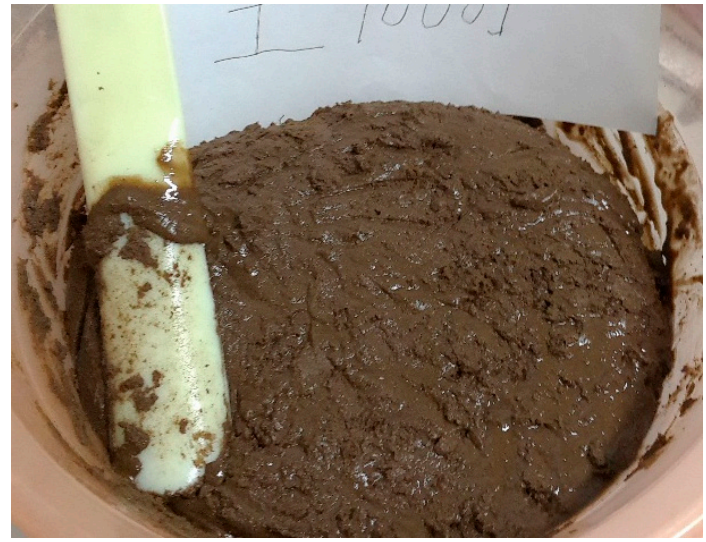

(b)

Figure 1. Viscous fluid composition: (a) silt; (b) mixture of methyl silicone oil and silt.

\subsection{Structure of the Dampers}

One type of damper (Damper 1) was designed and fabricated for a pre-test (based on a standard hydraulic cylinder), shown in Figure 2a. Two pores with diameter of $3 \mathrm{~mm}$ were punched on the piston. Then, by estimating the output force of the guide rod and the pressure on the piston plate, another type of damper (Damper 2) was designed to be tested by a different loading mechanism, which had a much higher loading capacity, shown in Figure 2b. Damper 2 had four pores with diameters of $5 \mathrm{~mm}$. 


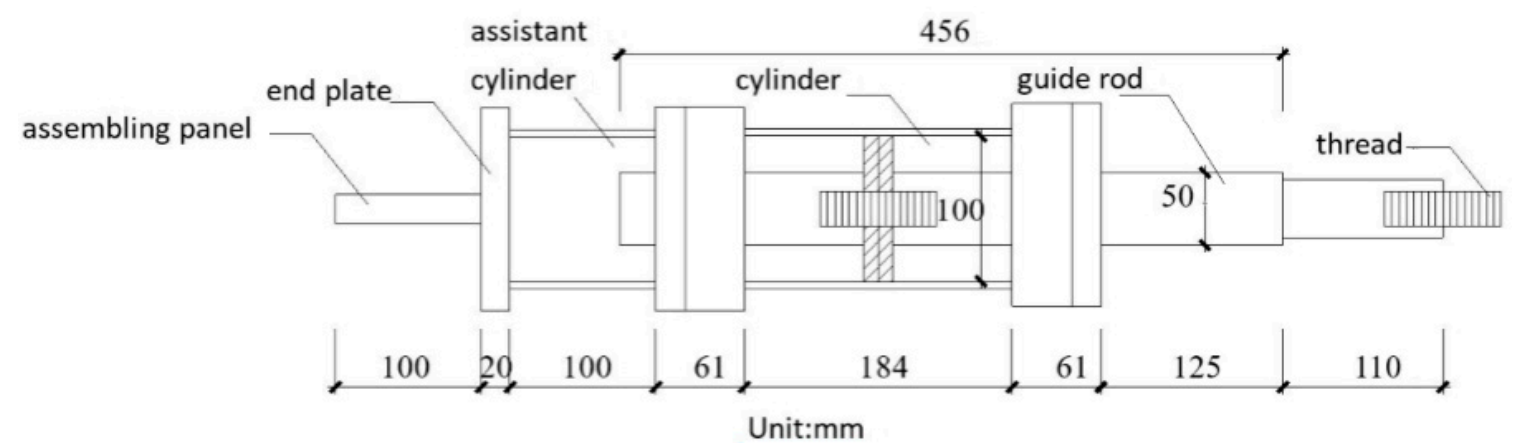

(a)

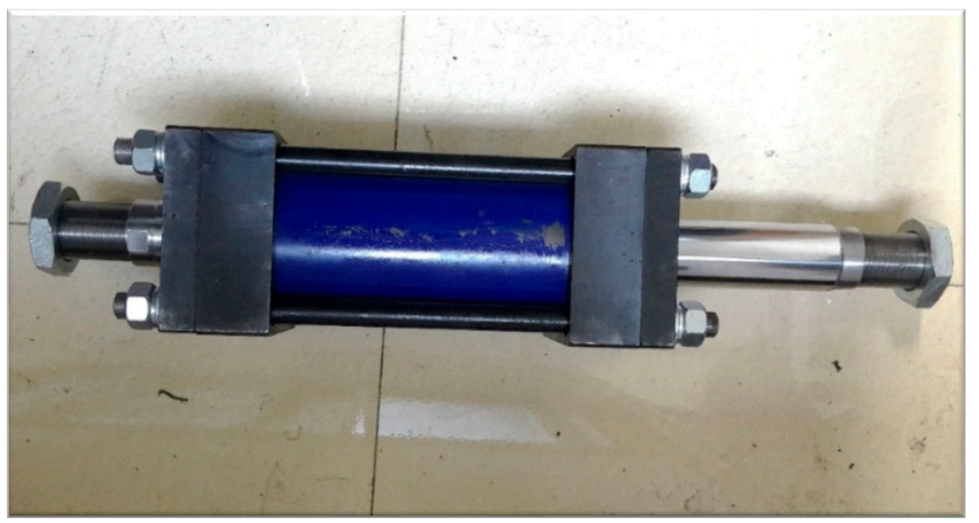

(b)

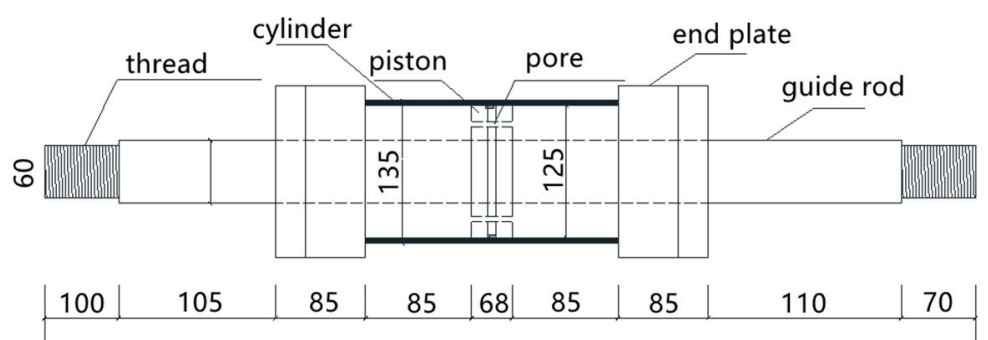

unit:mm

(c)
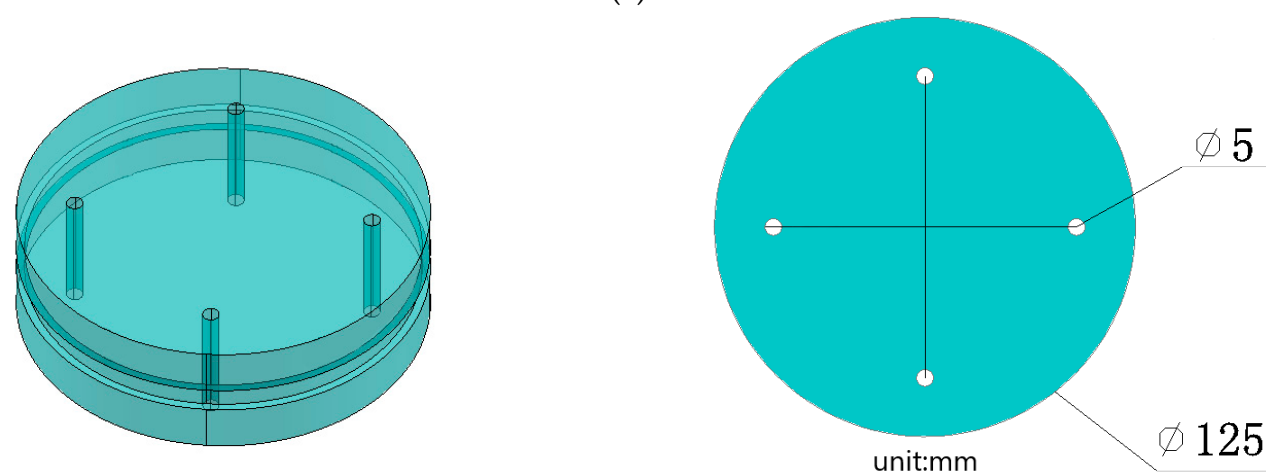

(d)

Figure 2. Structure of the dampers: (a) dimensions of Damper 1; (b) photo of Damper 2; (c) dimension of Damper 2; (d) piston of Damper 2. 


\subsection{The Sustainable Design}

As an easily obtainable material, silt not only enhances the seismic performance of the damper, but also offers sustainability. Fluid viscous dampers are unable to exhibit great performance for small displacements, and adding silt to the damping medium solves this problem. The mixture of silt and silicone oil can bring displacement-dependent features to the damper, which will be discussed in later sections. Compared to other solutions (such as using lever arms to magnify the displacement or installing other types of dampers), the proposed damper possesses the desired properties without the added costs of construction materials. In addition, when compared to semi-active or active dampers such as MR dampers, the proposed damper can work without additional energy. Hence, the addition of silt is an economical approach to enhance the performance of conventional viscous dampers.

\section{Experimental Study}

The cyclic loading test is a pseudo-static test and is one of the most important experimental methods to study seismic performance of structural systems or members. These tests aim to obtain properties such as energy dissipation capacity, hysteretic property and ductility, which are vital for earthquake-resilient design.

\subsection{Pre-Test}

Harmonic excitations (sine wave) with displacement amplitudes and loading frequencies equal to $20 \mathrm{~mm}$ and $0.1 \mathrm{~Hz}$ were applied for preliminary study of the damper. The loading system in this pre-test had a capacity of $10 \mathrm{kN}$ force. The loading procedure was controlled by displacement. Furthermore, Damper 1 was tested in two test conditions and each condition included 10 cycles. The damping medium of Condition\#1 was silicone oil while that of Condition\#2 was silicone oil with $30 \%$ silt (mass ratio).

The hysteretic curves of the two conditions are shown in Figure 3. The shapes of the two curves were similar. The maximum damping force of Condition\#1 and Condition\#2 was $0.79 \mathrm{kN}$ and $1.18 \mathrm{kN}$, respectively. The silt increased the damping force by $49.4 \%$.

In order to test this type of damper in more realistic operating conditions (large damping forces in real engineering projects), a formal large-scale experiment was planned. It sought to test dampers for small displacements $(3 \mathrm{~mm}, 5 \mathrm{~mm})$. Although the authors tried to test dampers without silt, the measured damping forces for small displacements $(3 \mathrm{~mm})$ were less than $2 \mathrm{kN}$ because conventional viscous dampers could not yield correspondingly high damping forces for small displacements [7]. Considering that the loading system possessed a high capacity of $100 \mathrm{kN}$ force, dampers without silt were not suitable to be tested in the formal experiment.

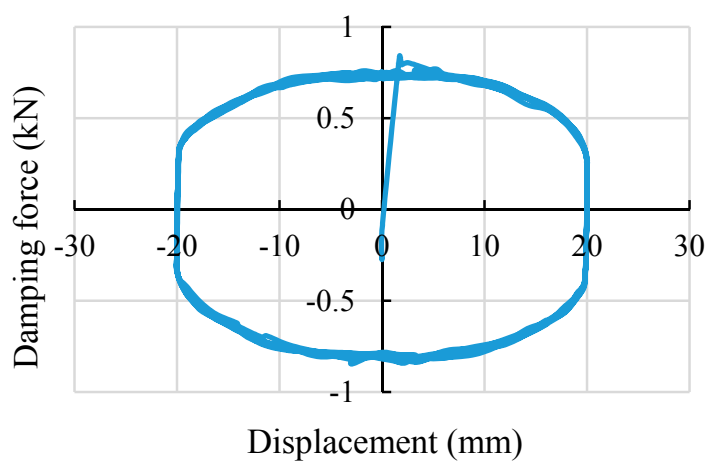

(a)

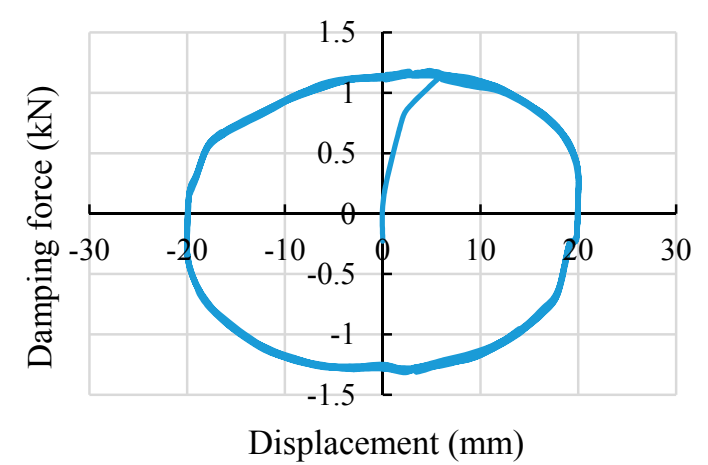

(b)

Figure 3. Hysteretic curves of the dampers in pre-test: (a) Condition\#1 (without silt); (b) Condition\#2 (with silt). 


\subsection{Test Setup of the Formal Experiment}

The loading procedure was consistent with the pre-test. The test variables were silt content (mass ratio), loading displacement, and loading frequency.

Damper 2 was studied in the formal experiment and test conditions were divided into three groups with the silt mass ratio being 30\%, 40\%, and 50\%, respectively. Orthogonal test in multiple loading conditions was applied to each group. The amplitude of the loading displacement varied from $3 \mathrm{~mm}$ to $20 \mathrm{~mm}$ and the loading frequency varied from $0.5 \mathrm{~Hz}$ to $2.0 \mathrm{~Hz}$. There was a total of 33 test conditions and each condition included 15 cycles. The loading displacement and the damping force were recorded during each loading cycle to examine the energy dissipation capacity of the damper under different excitations.

The MTS electro-hydraulic servo system was used in the formal experiment. As shown in Figure 4, the two blue plates were steel backing plates, connected to the reaction wall and the floor, respectively. The yellow part was the actuator; the green part was the damper, fixed on an I-shape steel by bolts; the I-shape steel was also connected to the backing plate by bolts; and the steel backing plate was secured to the floor using pre-tensioned bolts to minimize slips.
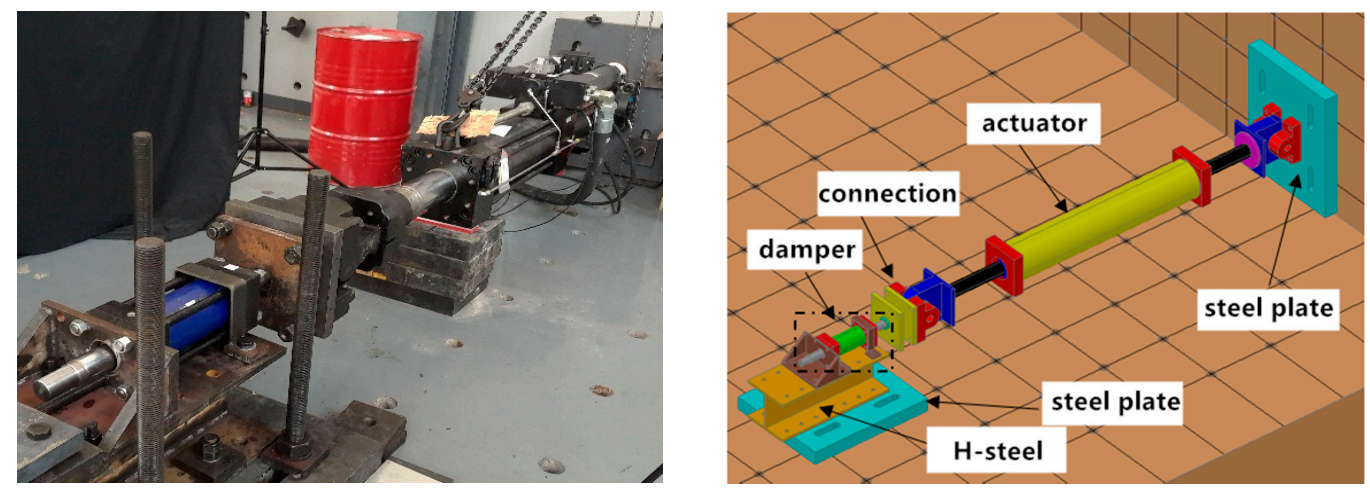

Figure 4. Test setup.

\subsection{Experimental Results}

\subsubsection{Hysteretic Curves}

Using the loading displacement as abscissa against the damping force as ordinate, the hysteretic curves under each test condition were drawn. The hysteretic curves of the three groups with different silt mass ratios were similar in how curves changed with displacement amplitude and loading frequency. Curves with silt mass ratio of $30 \%$ were presented as a typical case in Figure 5.

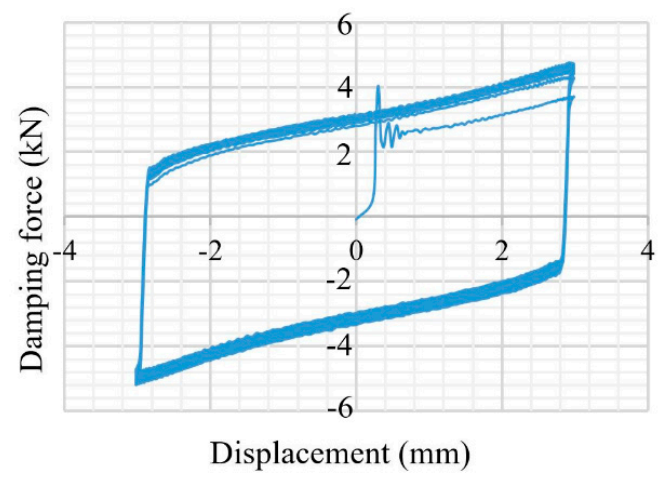

(a)

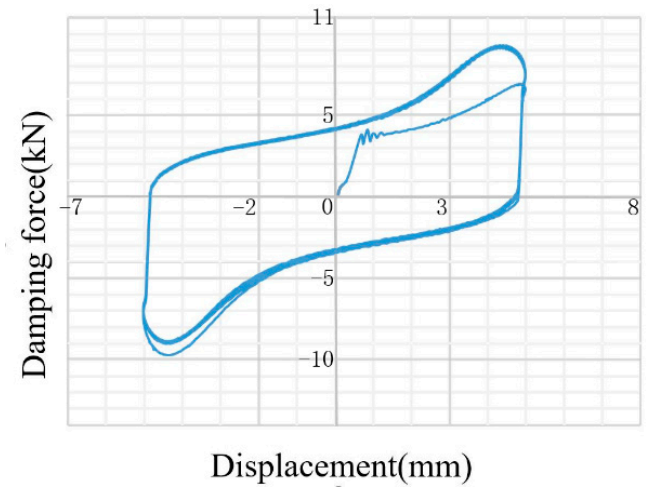

(b)

Figure 5. Cont. 


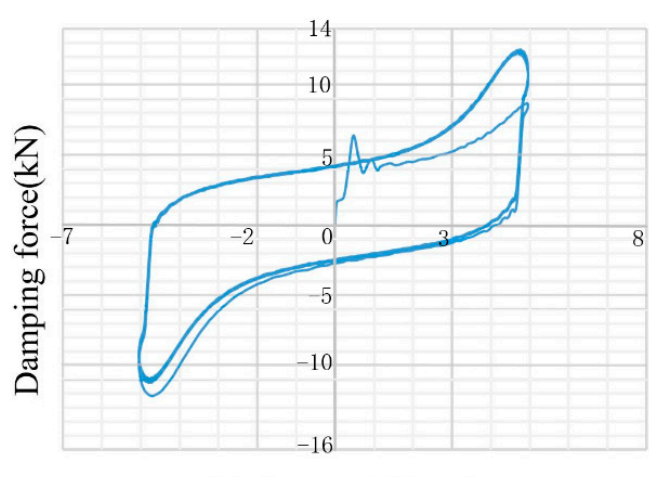

Displacement(mm)

(c)

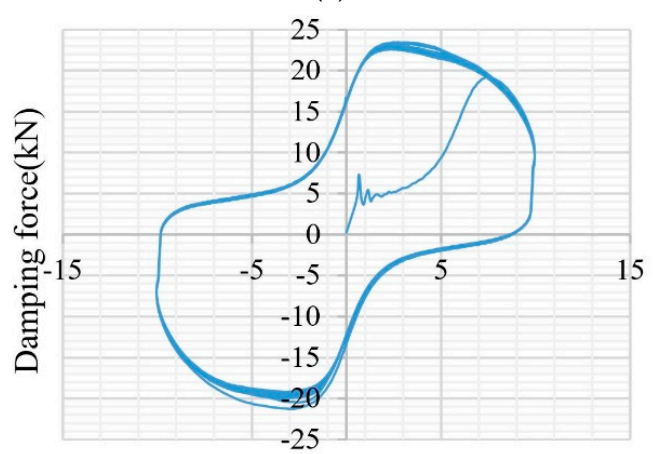

Displacement $(\mathrm{mm})$

(e)

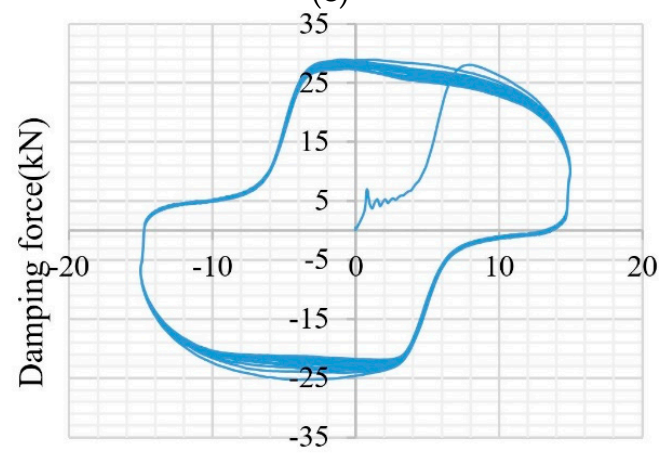

Displacement $(\mathrm{mm})$

(g)

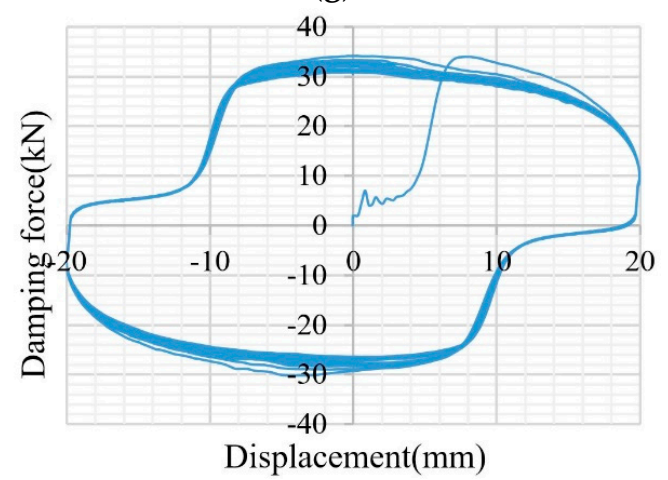

(i)

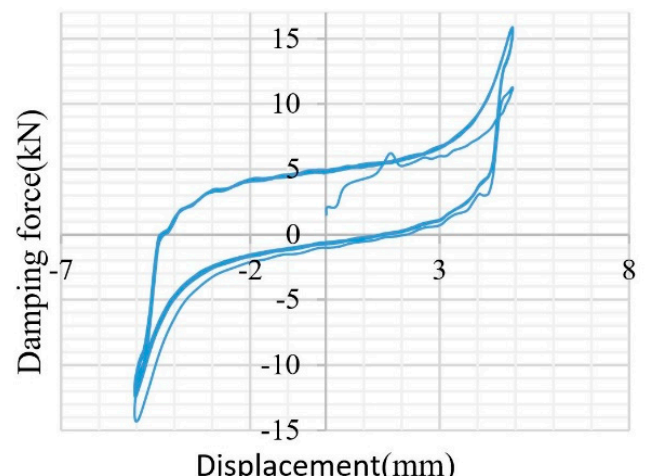

(d)

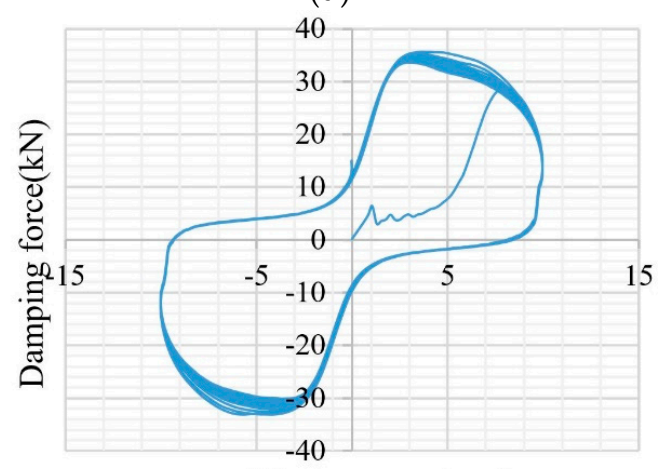

Displacement $(\mathrm{mm})$

(f)

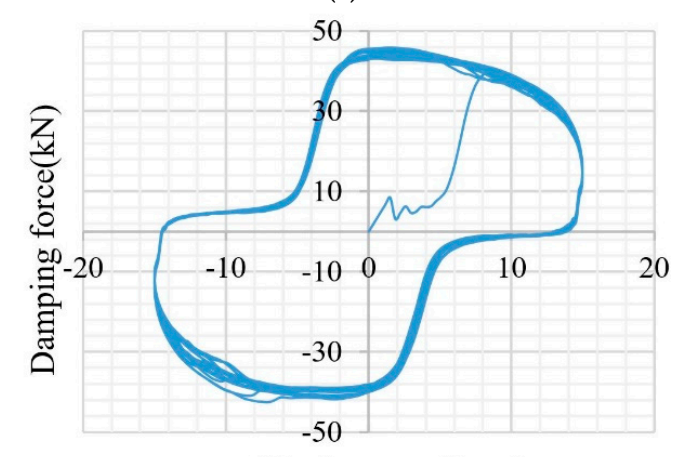

Displacement(mm)

(h)

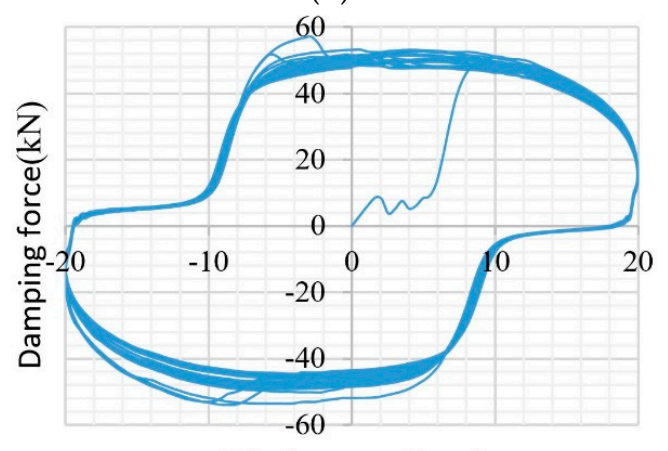

Displacement(mm)

(j)

Figure 5. Hysteretic curves (silt mass ratio $=30 \%$ ) (displacement amplitude, loading frequency): (a) $3 \mathrm{~mm}, 0.5 \mathrm{~Hz}$; (b) $5 \mathrm{~mm}, 0.5 \mathrm{~Hz}$; (c) $5 \mathrm{~mm}, 1.0 \mathrm{~Hz}$; (d) $5 \mathrm{~mm}, 2.0 \mathrm{~Hz}$; (e) $10 \mathrm{~mm}, 0.5 \mathrm{~Hz}$; (f) $10 \mathrm{~mm}$, $1.0 \mathrm{~Hz}$; (g) $15 \mathrm{~mm}, 0.5 \mathrm{~Hz}$; (h) $15 \mathrm{~mm}, 1.0 \mathrm{~Hz}$; (i) $20 \mathrm{~mm}, 0.5 \mathrm{~Hz}$; (j) $20 \mathrm{~mm}, 1.0 \mathrm{~Hz}$. 
By observing the changing process of the curves, it can be seen that when the amplitude of loading displacement was small, the curve was plump and the shape was similar to a parallelogram. With increase in amplitude, the curve became more rounded; then, despite the pinching phenomenon, the shape was closer to an oval. In conclusion, when the amplitude of loading displacement was large, the damper's energy dissipation model was close to the Kelvin model of the conventional viscous damper.

The difference between this hysteretic characteristic and that of a conventional viscous damper was that the damping force included not only a velocity-dependent viscous force but also a displacement-dependent hysteretic force. The displacement-dependent force was formed by the effective stress of the piston on the silt particles, which was related to the constitutive model of the silt. When the displacement was small, the energy was consumed by the elastic-plastic deformations of the silt. Hence, the hysteretic curve was close to a parallelogram, which was consistent with the elastic-plastic model of the silt. When the displacement was large, the damping force increased considerably as the silt increased the viscosity of the medium. Energy consumption also gradually showed velocity-dependent features and the damping force-displacement curve became an oval. Although the hysteretic curve under large displacement had a certain degree of pinching, the pattern of the change was still consistent with the expected result (that the energy dissipation mechanism was displacement-dependent for small displacement and velocity-dependent for large displacement). The pinching phenomenon was probably because the viscous medium was not dense enough, leading to the existence of porosity in the cylinder. In addition, it was also probably due to the plastic deformation ability of the medium. When the piston moved to one side, the viscous medium was unable to flow quickly through the pores to the other side of the cylinder. Hence, the other side was not fully filled by the damping medium.

\subsubsection{Effect of Silt Content}

As silt was the core difference between the proposed innovative viscous damper and the conventional one, the effect of the silt content on hysteretic curves was studied, as shown in Figure 6 . Despite pinching, the curves were similar and almost oval. The damping force was considerably increased with an increase in silt content (mass ratio). Furthermore, the silt also made the curves plumper. However, it was also observed that the silt intensified the pinching phenomenon to a certain extent.

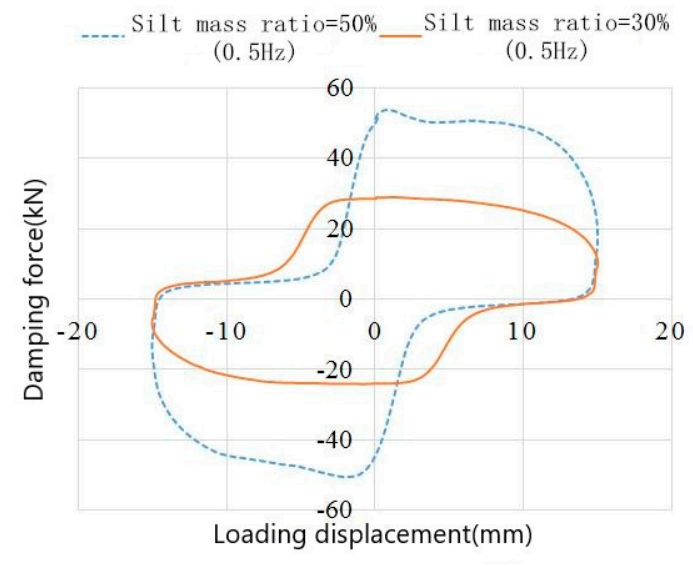

(a)

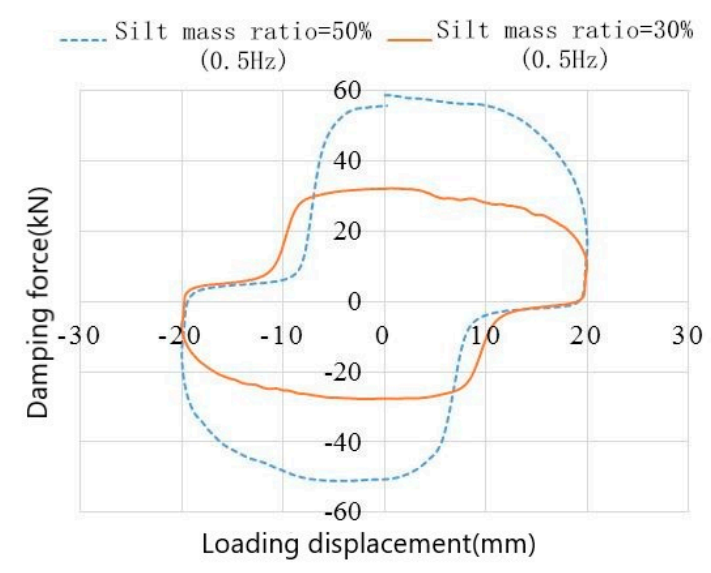

(b)

Figure 6. Comparison of the hysteretic curves with different silt contents: (a) displacement amplitude $=15 \mathrm{~mm}$; (b) displacement amplitude $=20 \mathrm{~mm}$. 
The relationship between the silt content and the maximum damper force is shown in Figure 7. When the displacement amplitude was $5 \mathrm{~mm}$, increasing the silt content did not visibly change the maximum damping force. When the amplitude was larger, the effect of the silt was more notable. This is because when the displacement was small, the main contribution of the silt was to dissipate energy by plastic deformation. This part of energy was small when compared to the total consumed energy, hence the damping force did not greatly increase. As the loading displacement continued to increase, the damping force gradually exhibited velocity-dependent characteristics. Since the silt considerably increased the viscosity of the medium, the growth of the damping force in large displacement positively correlated with an increase in silt content.

However, when the amplitude of displacement was $15 \mathrm{~mm}$, increasing silt content did not prove to be effective when the mass ratio exceeded $40 \%$, as too much silt weakened the fluidity of the medium, preventing it from passing thorough the pores.

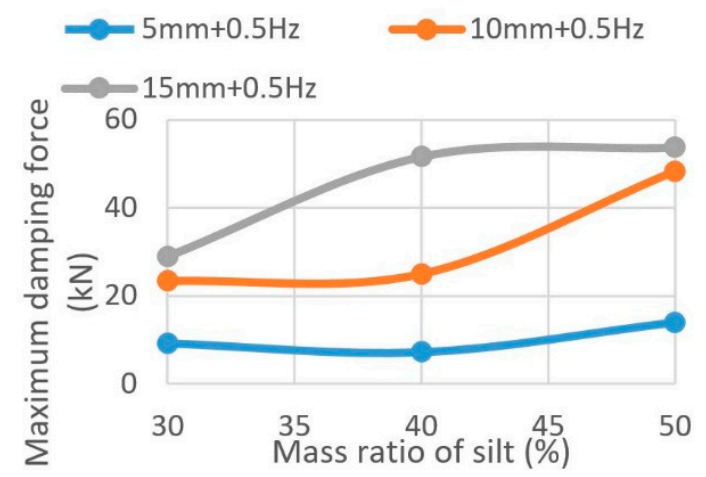

(a)

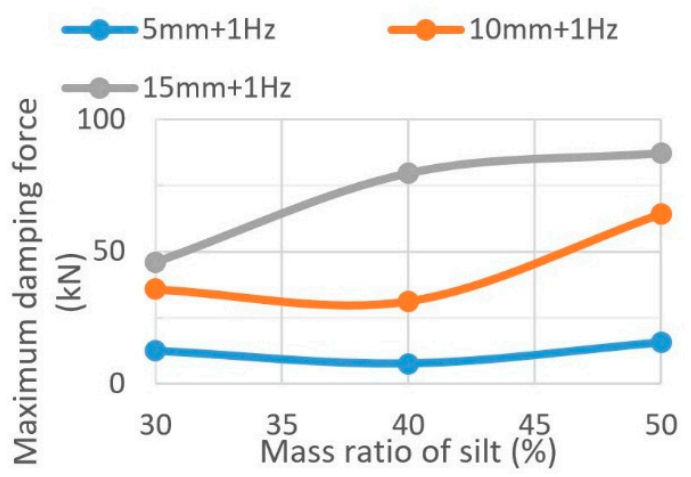

(b)

Figure 7. Relationship between the maximum damping force and the mass ratio of silt: (a) $0.5 \mathrm{~Hz}$; (b) $1.0 \mathrm{~Hz}$.

\subsubsection{Effect of Displacement Amplitude and Loading Frequency}

The effect of displacement amplitude and loading frequency on the maximum damping force is presented in Figures 8 and 9. It can be seen that, in general, the maximum damping force (Fmax) positively relates to displacement amplitude and loading frequency. However, it can still be seen that increasing loading frequency does not change Fmax visibly under small displacement amplitude, especially when the mass ratio of silt is large $(>40 \%)$. This phenomenon is consistent with the previous conclusion that the damper is displacement-dependent for small displacements.

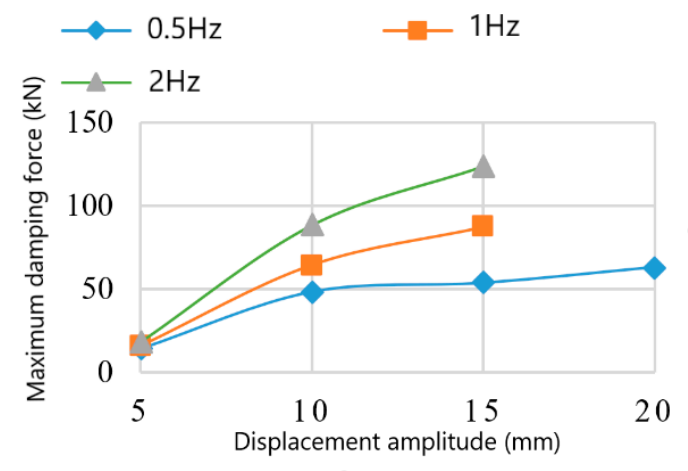

(a)

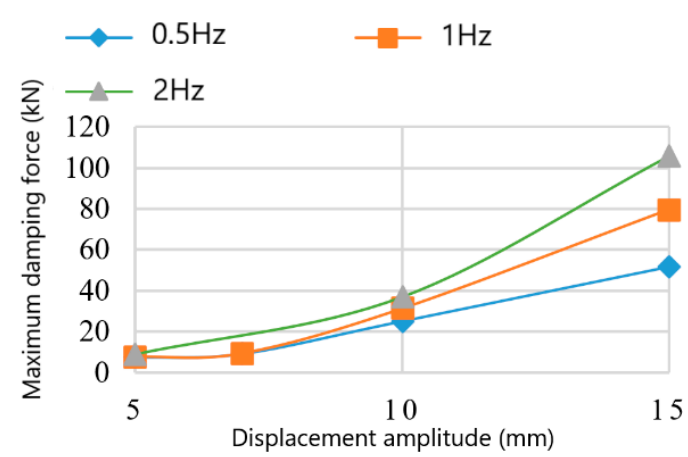

(b)

Figure 8. Cont. 


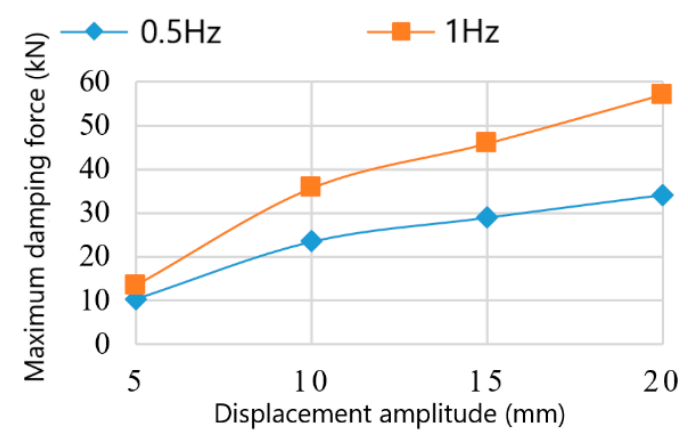

(c)

Figure 8. Relationship between the maximum damping force and the displacement amplitude: (a) mass ratio of silt $=50 \%$; (b) mass ratio of silt $=40 \%$; (c) mass ratio of silt $=30 \%$.

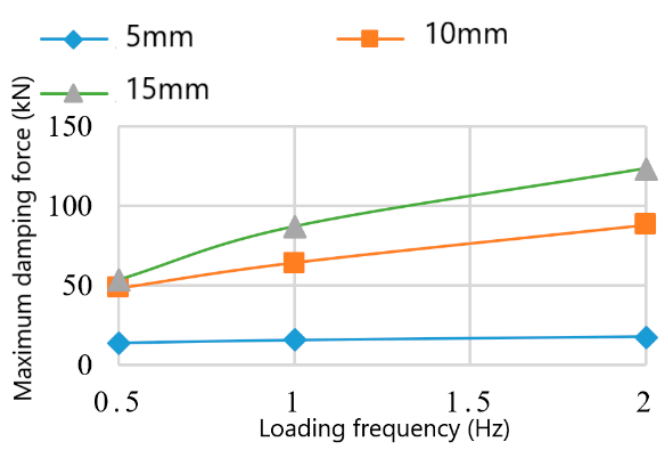

(a)

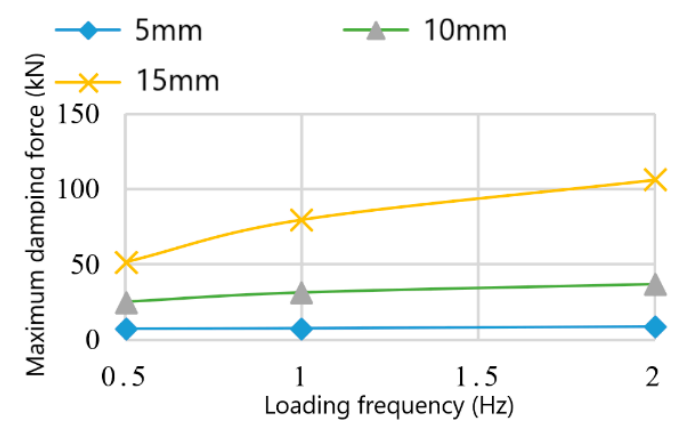

(b)

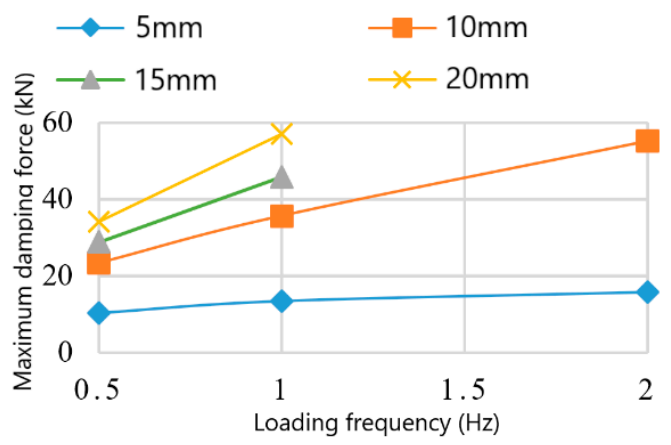

(c)

Figure 9. Relationship between the maximum damping force and the loading frequency: (a) mass ratio of silt $=50 \%$; (b) mass ratio of silt $=40 \%$; (c) mass ratio of silt $=30 \%$.

\section{Simulation Results and Discussion}

The damping force models of the damper under small and large displacements can be obtained using the least square method.

As discussed earlier, under small displacement, the silt can help improve the performance of the damper by providing displacement-dependent features. The new damper can offer better control of the vibration of the structure during minor earthquakes, proving to be meaningful for structural comfort design. Taking the test condition that loading displacement and frequency equals to $3 \mathrm{~mm}$ and $0.5 \mathrm{~Hz}$ as a sample, the relationship between damping force and displacement can be fitted as a bilinear model, as shown in Figure 10, where $K_{0}$ and $K_{d}$ represent the stiffness before and after yielding, respectively. Part of the experimental data is marked in Figure 10. 


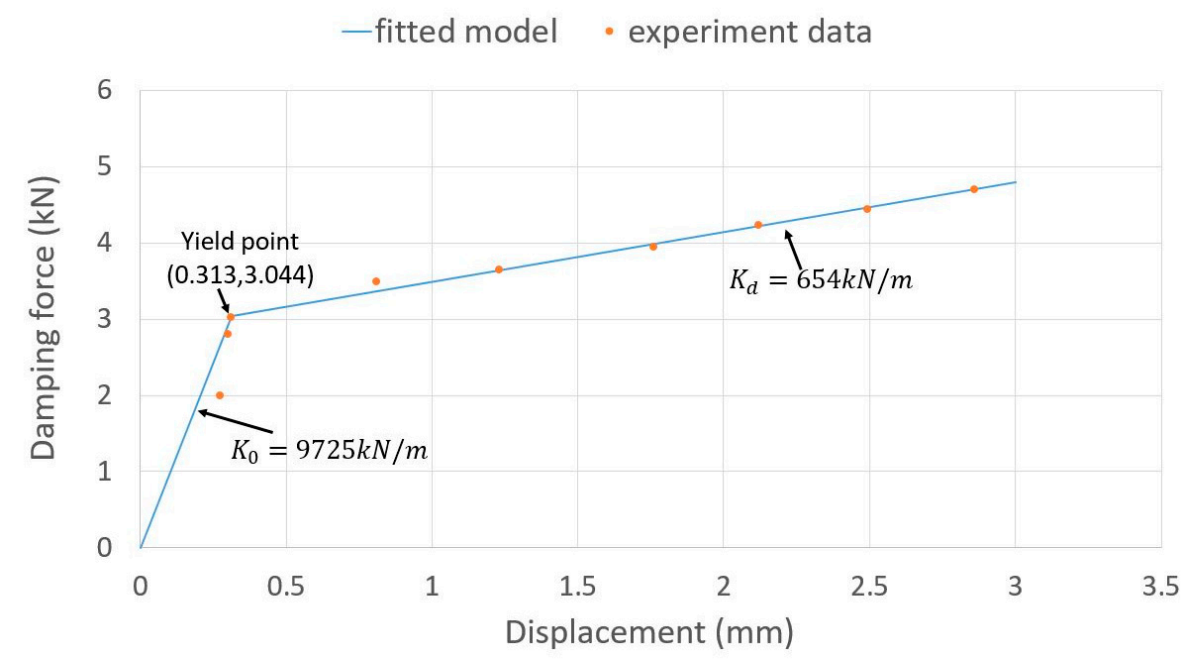

Figure 10. Fitted displacement-dependent model under a small displacement ( $3 \mathrm{~mm})$.

Structures suffer large displacements during major earthquakes, and dampers are hence designed to protect them from severe damage or collapse. In this case, the bearing capacity of the damper is critical. As discussed earlier, the damper shows velocity-dependent features under large displacements. The data of test condition that loading displacement and frequency equal to $20 \mathrm{~mm}$ and $0.5 \mathrm{~Hz}$ can be fitted as below:

$$
F=3.008 v^{0.5700}\left(\mathrm{~F} / \mathrm{kN}, v / \mathrm{mm} \cdot \mathrm{s}^{-1}\right)
$$

Velocity index is 0.57 , in the commonly used value range (0.3 1.95) [7]. The data of all test conditions with silt content of $30 \%$ are taken to verify the rationality of Equation (1). Part of the typical data in the first and third quadrants of the hysteretic curves is shown in Figure 11. The difference between the experimental results and the fitted value is within $15 \%$, indicating that the model can accurately predict the damping force.

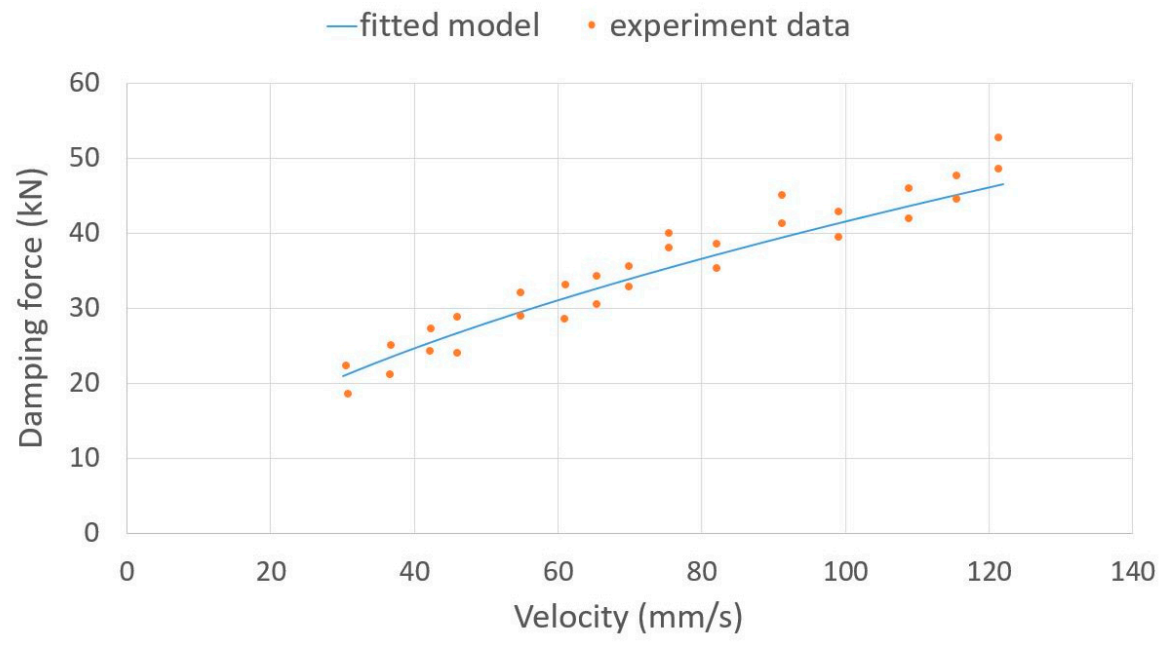

Figure 11. Fitted velocity-dependent model under large displacements.

\section{Conclusions}

This paper investigates a new type of viscous damper that adds silt to the damping medium to improve its energy dissipation performance. The energy dissipation mechanism of this damper is studied through a cyclic loading experiment. The following conclusions are drawn: 
(1) Silt can considerably increase damping force by enhancing the viscosity of the damping medium.

(2) Silt can enrich the energy dissipation mechanism of the damper. Experimental results show that the damper is displacement-dependent with a plump hysteretic curve for small displacements. This displacement-dependent feature can improve the energy consumption ability of fluid viscous dampers for small displacements. For large displacements, the damper is still velocity-dependent.

(3) Silt content has a great effect on the maximum damping force. Unless displacement is very small $(5 \mathrm{~mm})$, increasing the content of silt can visibly increase the damping force. However, the relationship between the damping forces and the silt content is complex, and not always positive. Further studies engaging more test groups are required to determine the optimum mass ratio of silt.

(4) For small displacements, the displacement-dependent damping force can be predicted by a bilinear model. For large displacements, the damping force is velocity-dependent and can be reasonably fitted.

Author Contributions: Zheng Lu wrote the paper and directed the study. Junzuo Li analyzed the data and revised the paper. Chuanguo Jia conceived the idea, carried out the experiment, provided valuable discussions and revised the paper. He took responsibility of the corresponding work.

Acknowledgments: The authors gratefully acknowledge the financial supports from the National Natural Science Foundation of China (No. 51408080).

Conflicts of Interest: The authors declare no conflict of interest.

\section{References}

1. Takewaki, I.; Fujita, K.; Yamamoto, K.; Takabatake, H. Smart passive damper control for greater building earthquake resilience in sustainable cities. Sustain. Cities Soc. 2011, 1, 3-15. [CrossRef]

2. Housner, G.W.; Bergman, L.A.; Caughey, T.K.; Chassiakos, A.G.; Claus, R.O.; Masri, S.F.; Skelton, R.E.; Soong, T.T.; Spencer, B.F.; Yao, J.T. Structural Control: Past, Present, and Future. J. Eng. Mech. 1997, 123, 897-971. [CrossRef]

3. Lu, Z.; Wang, Z.; Masri, S.F.; Lu, X. Particle impact dampers: Past, present, and future. Struct. Control Health Monit. 2018, 25, e2058. [CrossRef]

4. Lu, X.; Liu, Z.; Lu, Z. Optimization design and experimental verification of track nonlinear energy sink for vibration control under seismic excitation. Struct. Control Health Monit. 2017, 24, e2033. [CrossRef]

5. Segel, L.; Lang, H.H. The Mechanics of Automotive Hydraulic Dampers at High Stroking Frequencies. Veh. Syst. Dyn. 1982, 10, 82-85. [CrossRef]

6. Makris, N. Viscous Dampers: Testing Modeling and Application in Vibration and Seismic Isolation; Technical Report NCEER-90-0028; State University at Buffalo: Buffalo, NY, USA, 1990.

7. Lee, D.; Taylor, D.P. Viscous damper development and future trends. Struct. Des. Tall Spec. Build. 2010, 10, 311-320. [CrossRef]

8. Hundal, M.S. Impact absorber with two-stage, variable area orifice hydraulic damper. J. Sound Vib. 1977, 50, 195-202. [CrossRef]

9. Dyke, S.J.; Spencer, B.F., Jr.; Sain, M.K.; Carlson, J.D. An experimental study of MR dampers for seismic protection. Smart Mater. Struct. 1998, 7, 693-703. [CrossRef]

10. Mcnamara, R.J.; Taylor, D.P. Fluid viscous dampers for high-rise buildings. Struct. Des. Tall Spec. Build. 2003, 12, 145-154. [CrossRef]

11. Lu, Z.; Wang, Z.X.; Zhou, Y.; Lu, X.L. Nonlinear dissipative devices in structural vibration control: A review. J. Sound Vib. 2018, 423, 18-49. [CrossRef]

12. Constantinou, M.C.; Symans, M.D. Experimental and Analytical Investigation of Seismic Response of Structures with Supplemental Fluid Viscous Dampers; Technical Report; National Center for Earthquake Engineering Research: Buffalo, NY, USA, 1992.

13. Makris, N.; Constantinou, M.C. Fractional-Derivative Maxwell Model for Viscous Dampers. J. Struct. Eng. 1991, 117, 2708-2724. [CrossRef] 
14. Taylor, D.P.; Constantinou, M.C. Testing Procedures for High Output Fluid Viscous Dampers Used in Building and Bridge Structures to Dissipate Seismic Energy. Shock Vib. 1995, 2, 373-381. [CrossRef]

15. Uetani, K.; Tsuji, M.; Takewaki, I. Application of an optimum design method to practical building frames with viscous dampers and hysteretic dampers. Eng. Struct. 2003, 25, 579-592. [CrossRef]

16. López, I.; Busturia, J.M.; Nijmeijer, H. Energy dissipation of a friction damper. J. Sound Vib. 2004, 278, 539-561. [CrossRef]

17. Xu, Y.L.; Qu, W.L.; Chen, Z.H. Control of Wind-Excited Truss Tower Using Semiactive Friction Damper. J. Struct. Eng. 2001, 127, 861-868. [CrossRef]

18. Narkhede, D.I.; Sinha, R. Behavior of nonlinear fluid viscous dampers for control of shock vibrations. J. Sound Vib. 2014, 333, 80-98. [CrossRef]

19. Abbas, H. A Methodology for Design of Viscoelastic Dampers in Earthquake-Resistant Structures; Earthquake Engineering Research Center, University of California: Santa Barbara, CA, USA, 1993.

20. Berton, S.; Bolander, J.E. Amplification System for Supplemental Damping Devices in Seismic Applications. J. Struct. Eng. 2005, 131, 979-983. [CrossRef]

21. Ribakov, Y.; Reinhorn, A.M.; Asce, F. Design of amplified structural damping using optimal considerations. J. Struct. Eng. 2003, 129, 1422-1427. [CrossRef]

22. Dai, K.; Wang, J.; Mao, R.; Lu, Z.; Chen, S. Experimental investigation on dynamic characterization and seismic control performance of a TLPD system. Struct. Des. Tall Spec. Build. 2017, 26, e1350. [CrossRef]

23. Lu, Z.; Yang, Y.; Lu, X.; Liu, C. Preliminary Study on the Damping Effect of a Lateral Damping Buffer under a Debris Flow Load. Appl. Sci. 2017, 7, 201. [CrossRef]

24. Tsai, C.S.; Chen, K.C.; Chen, C.S. Seismic Resistibility of High-Rise Buildings with Combined Velocity-Dependent and Velocity-Independent Devices; ASME: New York, NY, USA, 1998; pp. 103-110.

25. Julius, M.; David, T.; Nimal, P. Influence of damping systems on building structures subject to seismic effects. Eng. Struct. 2004, 26, 1939-1956.

26. Lu, Z.; Lu, X.; Masri, S.F. Studies of the performance of particle dampers under dynamic loads. J. Sound Vib. 2010, 329, 5415-5433. [CrossRef]

27. Lee, J.; Kang, H.; Kim, J. Seismic performance of steel plate slit-friction hybrid dampers. J. Constr. Steel Res. 2017, 136, 128-139. [CrossRef]

28. Kim, J.; Shin, H. Seismic loss assessment of a structure retrofitted with slit-friction hybrid dampers. Eng. Struct. 2017, 130, 336-350. [CrossRef]

29. Lu, Z.; Huang, B.; Zhou, Y. Theoretical study and experimental validation on the energy dissipation mechanism of particle dampers. Struct. Control Health Monit. 2018, 25, e2125. [CrossRef]

30. Lu, Z.; Chen, X.Y.; Zhang, D.C.; Dai, K.S. Experimental and analytical study on the performance of particle tuned mass dampers under seismic excitation. Earthq. Eng. Struct. Dyn. 2017, 46, 697-714. [CrossRef]

31. Hardin, B.O.; Drnevich, V.P. Shear modulus and damping in soil: Measurement and parameter effects. ASCE Soil Mech. Found. Div. J. 1972, 98, 603-624.

32. Hardin, B.O.; Drnevich, V.P. Shear Modulus and Damping in Soils: Design Equations and Curves. J. Soil Mech. Found. Div. 1972, 98, 667-692.

33. Crouse, C.B.; Mcguire, J. Energy dissipation in soil-structure interaction. Earthq. Spectra 2001, 17, $235-259$. [CrossRef]

34. Kaare, H.; Rune, D.; Sandbakken, G. Strength of Undisturbed versus Reconstituted Silt and Silty Sand Specimens. J. Geotech. Geoenviron. Eng. 2000, 126, 606-617.

35. Iravanai, S. Geotechnical Characteristics of Penticton Silt. Ph.D. Thesis, University of Alberta, Edmonton, AB, Canada, 1999.

(C) 2018 by the authors. Licensee MDPI, Basel, Switzerland. This article is an open access article distributed under the terms and conditions of the Creative Commons Attribution (CC BY) license (http:/ / creativecommons.org/licenses/by/4.0/). 